\title{
Recognizing Homicide as a Public Health Threat
}

\author{
Toward an Integration of Sociological and Public \\ Health Perspectives in the Study of Violence
}

\author{
WILLIAM ALEX PRIDEMORE \\ University of Oklahoma
}

\begin{abstract}
This article establishes the burden of violent mortality worldwide and discusses the possibility of integrating public health and sociological criminology in the study of violence. First, vital statistics data are employed to outline the worldwide burden of violent mortality and reveal nations and population subgroups that exhibit high rates of homicide victimization. Second, the contributions of sociological criminology and public health to the study of violence are described. In general, the sociological approach provides a theoretically driven understanding of the causal structure of the social processes that generate variation in homicide rates. The public health perspective, on the other hand, employs a wide variety of methods to present concrete intervention strategies to reduce and prevent harm. Integration of these two approaches should result in theoretical advancement in our comprehension of the causes of lethal violence and in practical applications that will reduce the excess morbidity and mortality due to violence and the public health burden it presents.
\end{abstract}

Keywords: homicide; criminology; public health; violence

Sociologists and criminologists who study violence sometimes stray into the public health and epidemiological literature, especially for issues relating to measurement and methodology. Those who do soon notice that in attempts to explain different types of health outcomes, public health researchers often examine exposure to

AUTHOR'S NOTE: This research was supported in part by a Junior Faculty Research Fellowship from the Office of the Vice-President for Research at the University of Oklahoma. The points of view are those of the author and do not necessarily reflect the official position of the grantor. An earlier version of this article was presented at the General Population Conference of the International Union for the Scientific Study of Population, August 2001, Salvador de Bahia, Brazil. I thank Vladimir Shkolnikov and Jim Mercy for their intellectual input into these ideas and their critiques of earlier drafts of this article.

HOMICIDE STUDIES, Vol. 7 No. 2, May 2003 182-205

DOI: $10.1177 / 1088767903251105$

(C) 2003 Sage Publications

182 
many of the same socioenvironmental risks that we discuss in relation to violent outcomes. One will also find in this literature public health and epidemiological studies that directly examine violence-related morbidity and mortality. Most are rigorous and present a fresh approach, but it is common to discover lapses or problems that are already well recognized by traditional sociologists and criminologists.

On the other hand, it has become impossible to read sociological and criminological literature on crime and violence without noticing the use of language such as the risk and protective factors of offending and victimization (Hawkins, Catalano, \& Miller, 1992; Thornberry, Huizinga, \& Loeber, 1995), the diffusion of violence across populations (Messner et al., 1999), the role of contagion in antisocial behavior (Jones \& Jones, 2000; Loftin, 1986), and the epidemic of violence among young Black men in the United States from the mid-1980s to the early 1990s (Cook \& Laub, 1998), all of which sound much like the public health literature. The articles cited here represent important work, but as one reads through similar literature, it is clear that many sociologists and criminologists are also struggling over issues that our public health counterparts have already recognized.

Another glaring point, and the one mainly responsible for this situation, is that there is very little citation of work across these two perspectives. Both sides are wasting important scientific energy because they are either unaware of the other's literature or too discipline centered to lend it credence. ${ }^{1}$ Researchers doing work on violence that crosses these boundaries have been around for at least a century, but have been few and far between. The past several years, however, have seen a growth in areas such as social epidemiology (see Berkman \& Kawachi, 2000) and the attempt to merge the social and behavioral sciences with a public health approach (see Schneiderman, Speers, Silva, Tomes, \& Gentry, 2001). Much of the more recent work in this vein emanates from the findings presented in The Global Burden of Disease (Murray \& Lopez, 1996), which reveal the significance of injuries to public health and the role of intentional injuries within this category.

Although there have been very few attempts to integrate the two, several researchers have recognized the importance of violence as a public health problem, and public health officials are beginning to come aboard. Furthermore, several sociologists and 
criminologists who study violence have also recognized the importance of public health approaches, especially the idea of risk and protective factors, as well as violence reduction strategies. Unfortunately, there has been little in the way of conceptual integration of the two. This integration is vital and should be synergistic, because each perspective contains invaluable knowledge and methodologies concerning our understanding of and response to violence that may have yet to be shared.

This introductory and conceptual article is meant to encourage debate over the potential benefits and drawbacks to this integration, and it follows the lead of recent work that attempts to combine sociology/criminology and health (Kawachi, Kennedy, \& Wilkinson, 1999; Mercy \& Hammond, 1998; Ross, 1993; Schneiderman et al., 2001). The article begins with an examination of the burden of violence-related morbidity and mortality worldwide, including a discussion of nations and populations with high levels of homicide mortality, and an outline of suspected causes of these high rates. This is followed by a discussion of the advantages provided by the sociological and public health perspectives, some of their often-unrecognized similarities, and the benefits they can provide to each other and to our overall understanding of the causes of violence.

\section{THE BURDEN OF VIOLENCE}

Injuries are a leading cause of death worldwide, with an annual mortality rate of around 100 per 100,000 population (Krug, 1999), and the Forty-Ninth World Health Assembly in 1996 declared violence a public health concern. Table 1 outlines injury-related mortality throughout the world. Included together, interpersonal violence and war-related deaths constituted nearly one fourth of this total in 1998 (22.5 per 100,000) and represented the largest proportion of the injury category, outranking road traffic injuries (19.9 per 100,000). ${ }^{2}$ Interpersonal violence alone is the third leading cause of death in the injury category. Males suffer this fate at a disproportionately higher rate than females. The worldwide male mortality rate from interpersonal violence in 1998 was 19.6 per 100,000 and 11.6 from war-related injuries and deaths, with corresponding female rates of 5.3 and 8.4, respectively. 
TABLE 1

Estimated Injury-Related Mortality Worldwide, in Deaths per 100,000 Population, 1998

\begin{tabular}{lcrr}
\hline \hline & Both Genders & Males & Females \\
\hline All injuries & 97.9 & 128.6 & 66.7 \\
Road traffic & 19.9 & 28.8 & 10.8 \\
Suicide & 16.1 & 19.1 & 13.1 \\
Homicide & 12.5 & 19.6 & 5.3 \\
War & 10.0 & 11.6 & 8.4 \\
Drowning & 8.4 & 11.2 & 5.6 \\
Falls & 5.4 & 6.0 & 4.7 \\
Fires & 4.8 & 4.0 & 5.6 \\
Poisonings & 4.3 & 5.2 & 3.3 \\
Other injuries & 16.6 & 23.1 & 10.0 \\
\hline
\end{tabular}

SOURCE: Adapted from Krug (1999), Appendix 4.

Excess mortality due to violence disproportionately influences a population's life expectancy, because victims of violence tend to be younger than those dying of internal causes. Thus, even though its ranking as a cause of death may be relatively low in some age- and gender-specific categories, it is often a leading cause of total years of potential life lost. This can play a major role in a nation's development in several respects, and this is generally illustrated in the United Nations' human development index, because life expectancy is one of its three indicators (United Nations Development Programme, 2001). Disaggregating by world region and average country income also provides insight into the distribution of violence-related mortality (see later discussion of Table 3). In Africa, for example, war-related deaths are the leading injury-related cause of death and, with the exception of the United States, higher-income countries with established market economies tend to have lower rates of homicide mortality than lower-income nations (Neapolitan, 1998; Reza, Mercy, \& Krug, 2001; see also Table 2).

These basic estimates reveal that intentional violent injuries contribute substantially to overall mortality worldwide. ${ }^{3}$ Mortality estimates by cause further suggest that violent death is one of the main reasons there has been little reduction during the past 20 to 30 years in the overall mortality rates among those age 20 years to 50 years. The burden of violence, however, goes well beyond individual death and group mortality rates. Mercy and Hammond (1998), for example, cite as one of the many reasons 
TABLE 2

Estimated Homicide Mortality per 100,000 Population in Selected Nations

\begin{tabular}{|c|c|c|c|}
\hline Country & Homicides & Reporting Year & Income Level \\
\hline Argentina & 4.6 & 1996 & UM \\
\hline Armenia & 2.5 & 1997 & $\mathrm{~L}$ \\
\hline Australia & 1.6 & 1995 & $\mathrm{H}$ \\
\hline Austria & 1.1 & 1996 & $\mathrm{H}$ \\
\hline Azerbaijan & 6.3 & 1997 & $\mathrm{~L}$ \\
\hline Belarus & 11.5 & 1998 & LM \\
\hline Belgium & 1.4 & 1994 & $\mathrm{H}$ \\
\hline Brazil & 25.8 & 1995 & UM \\
\hline Bulgaria & 3.5 & 1998 & LM \\
\hline Canada & 1.4 & 1997 & $\mathrm{H}$ \\
\hline Colombia & 88.0 & 1993 & LM \\
\hline Costa Rica & 9.1 & 1995 & UM \\
\hline Croatia & 2.5 & 1997 & UM \\
\hline Cuba & 6.1 & 1996 & LM \\
\hline Czech Republic & 1.5 & 1998 & UM \\
\hline Denmark & 1.1 & 1996 & $\mathrm{H}$ \\
\hline England and Wales & 0.5 & 1997 & $\mathrm{H}$ \\
\hline Estonia & 16.4 & 1998 & UM \\
\hline Finland & 4.6 & 1996 & $\mathrm{H}$ \\
\hline France & 1.0 & 1996 & $\mathrm{H}$ \\
\hline Germany & 0.9 & 1996 & $\mathrm{H}$ \\
\hline Greece & 1.4 & 1997 & $\mathrm{H}$ \\
\hline Hungary & 3.0 & 1998 & UM \\
\hline Iceland & 0.0 & 1995 & $\mathrm{H}$ \\
\hline Ireland & 0.9 & 1996 & $\mathrm{H}$ \\
\hline Israel & 1.0 & 1996 & $\mathrm{H}$ \\
\hline Italy & 1.4 & 1995 & $\mathrm{H}$ \\
\hline Japan & 0.6 & 1997 & $\mathrm{H}$ \\
\hline Kazakhstan & 18.7 & 1997 & LM \\
\hline Kyrgyzstan & 8.9 & 1998 & $\mathrm{~L}$ \\
\hline Latvia & 11.9 & 1998 & UM \\
\hline Lithuania & 8.6 & 1997 & UM \\
\hline Luxembourg & 0.5 & 1997 & $\mathrm{H}$ \\
\hline Macedonia & 2.2 & 1997 & LM \\
\hline Malta & 0.4 & 1997 & UM \\
\hline Mauritius & 1.7 & 1997 & UM \\
\hline Moldova & 13.6 & 1996 & $\mathrm{~L}$ \\
\hline The Netherlands & 1.3 & 1997 & $\mathrm{H}$ \\
\hline New Zealand & 1.8 & 1996 & $\mathrm{H}$ \\
\hline Northern Ireland & 1.5 & 1997 & $\mathrm{H}$ \\
\hline Norway & 1.0 & 1995 & $\mathrm{H}$ \\
\hline Poland & 2.5 & 1996 & UM \\
\hline Portugal & 1.2 & 1998 & $\mathrm{H}$ \\
\hline Romania & 3.1 & 1998 & LM \\
\hline Russia & 22.2 & 1997 & LM \\
\hline Scotland & 1.7 & 1997 & $\mathrm{H}$ \\
\hline
\end{tabular}


TABLE 2 (continued)

\begin{tabular}{lccc}
\hline \hline Country & Homicides & Reporting Year & Income Level \\
\hline Singapore & 1.5 & 1995 & $\mathrm{H}$ \\
Slovak Republic & 2.0 & 1997 & $\mathrm{UM}$ \\
Slovenia & 2.0 & 1997 & $\mathrm{H}$ \\
Spain & 1.3 & 1995 & $\mathrm{H}$ \\
Sweden & 1.2 & 1996 & $\mathrm{H}$ \\
Switzerland & 1.1 & 1996 & $\mathrm{H}$ \\
Ukraine & 11.3 & 1998 & $\mathrm{~L}$ \\
United States & 7.6 & 1997 & $\mathrm{H}$ \\
\hline
\end{tabular}

SOURCE: World Health Organization (2001a).

NOTE: $\mathrm{L}=$ low income; $\mathrm{LM}=$ lower-middle income; $\mathrm{UM}=$ upper-middle income; $\mathrm{H}=$ high income. These are the only nations for which data are available from the World Health Organization during these years. Using 2001 figures, the World Bank (2002) calculates income level based on gross national product (GNP) per capita. Low income was less than $\$ 745$, middle income from $\$ 745$ to $\$ 9,206$, and high-income greater than $\$ 9,206$. The middle-income category is divided into low- and high-middle, the former being from $\$ 746$ to $\$ 2,975$ and the latter from $\$ 2,976$ to $\$ 9,206$. The rate for Brazil is from the reporting regions of the South, Southeast, and Midwest. The rate for Colombia is as reported in Villaveces et al. (2000).

why violence rests squarely within the public health domain the presence of a dose-response relationship. ${ }^{4}$ In other words, there is accumulating evidence that direct and indirect exposure to violence in childhood is a risk factor not only for delinquency (Kaufman \& Widom, 1999) and violence as an adult (Widom, 1989), but also on adult mental health (Horwitz, Widom, McLaughlin, \& White, 2001) and other health problems (Felitti et al., 1998).

Furthermore, high rates of violence create fear, uncertainty, and stress among community members, thereby negatively influencing individual health (Ross, 1993). Community vitality is also at risk, as levels of social cohesion are adversely affected (Adams \& Serpe, 2000) and the chances of economic development diminished. Thus, in areas with high levels of violence, fundamental social institutions (such as the family, community, education, and the economy) are constantly under attack.

Families of the victim and the convicted offender also suffer the psychological anguish and economic burdens associated with the death or incarceration of a loved one. Psychological and emotional health are often an issue with offenders as well, because a large proportion of those incarcerated for violent offenses exhibit mental health problems, underlying and as a result of confinement (Toch, 1992; Toch \& Adams, 1991). This is exacerbated by the 
poor health conditions and dangers, physical and mental, to which offenders are often subjected in prisons. Other covariates among those groups with high levels of homicide include alcohol and drug use. These not only create serious health burdens themselves but also represent risk factors for violence through various pathways, because it is common for either the homicide victim, offender, or both to be under the influence at the time of the event (see Cherpitel, 1993; MacDonald, Wells, Geisbrecht, \& Cherpitel, 1999; Rivara et al., 1997; Skog, 1986). Finally, there are the enormous costs associated with the private and public response to violence, including physicians, hospitals, prisons, police, and protective security services and devices (including weapons). Cook and Ludwig (2000), for example, estimated that the annual cost of gun violence alone is about $\$ 100$ billion in the United States.

Researchers and public health officials must make the same shift with homicide and other violence that was made with "accidents" many years ago (and diseases before that). Individual homicide events may seem random, but when examined more closely, homicide rates exhibit demographic, temporal, and spatial patterns and are conditioned not only by individual but also community, situational, and social structural characteristics. Although much work is left to be done and further complexities examined, the literature on the relationship between social structure and violence has matured substantially during the past three decades. This research is beginning to reveal the causal structure underlying variation in homicide rates, highlighting the reasons for the patterned nature of these events (for extensive reviews of this literature, see Messner \& Rosenfeld, 1999; Pridemore, 2002; Sampson \& Lauritsen, 1994). Homicide is thus an avoidable cause of death that can be mitigated with concerted policies and prevention techniques. Adding a public health perspective to this work will be of tremendous benefit in translating what we know about the causes of violence into effective practices for its reduction and prevention.

\section{Nations and Populations With High Levels of Excess Mortality From Lethal Violence}

Homicide is a leading cause of death and a major contributor to excess mortality in many nations and subnational populations. 
The effect of homicide on public health varies tremendously among nations and among different demographic groups. Table 2 provides a partial list of national homicide mortality rates according to World Health Organization data. It should be noted here that these are often tenuous estimates that are being presented not to compare rates of nations but instead to establish the very serious threat of violent mortality in certain nations.

Homicide rates reached nearly 90 per 100,000 population in Colombia in the 1990s, and in 1993, homicides represented two thirds of all deaths of Colombian males age 15 years to 44 years (Villaveces et al., 2000). Other nations with rates more than 10 per 100,000 include Brazil (25.8), Russia (22.2), Kazakhstan (18.7), Estonia (16.4), Moldova (13.6), Latvia (11.9), Belarus (11.5), and Ukraine (11.3). As can be seen, several nations of the former Soviet Union have very high rates of homicide mortality (a specific example of this will be discussed later).

The Global Burden of Disease Project estimated that there were around 560,000 homicides worldwide in 1990, for a rate of about 10.5 per 100,000 population (Reza et al., 2001). These interpersonal homicides accounted for $30 \%$ of all violent deaths (other causes included in this category are suicide and war-related deaths). Table 3 shows that rates were highest in the nations of sub-Saharan Africa and Latin America, with rates of homicide mortality at 45 and 22 per 100,000, respectively, and lowest in the established market economies (excluding the United States), which had a collective rate of 1 per 100,000. The homicide mortality rate in the United States that year was 10 times higher than in its fellow established market economy nations.

Age- and gender-specific homicide rates were highest for young men age 15 years to 29 years. Among females, children age 0 years to 4 years had the highest homicide mortality rates. High rates of female infanticide are likely the result of the relative devaluing of the lives of girls and women in certain cultures, as well as the specific cultural and political ramifications of the onechild policy in China (Johnson, 1996; United Nations Centre for Human Rights, 1996). Despite the peaks in these particular age and gender categories, homicide mortality rates and the patterns of homicide as a function of age vary substantially from nation to nation. 
TABLE 3

Estimated Age-Adjusted Mortality Rates From Interpersonal Homicide and War-Related Violent Deaths by World Region, in Deaths per 100,000 Population, 1990

\begin{tabular}{lcccc}
\hline \hline & $\begin{array}{c}\text { Homicide } \\
\text { Mortality } \\
\text { Rate }\end{array}$ & $\begin{array}{c}\text { Mortality } \\
\text { Due to } \\
\text { Homicide }\end{array}$ & $\begin{array}{c}\text { War-Related } \\
\text { Violent } \\
\text { Mortality } \\
\text { Rate }\end{array}$ & $\begin{array}{c}\text { \% of Overall } \\
\text { Mortality } \\
\text { Due to War- } \\
\text { Related Violence }\end{array}$ \\
\hline $\begin{array}{l}\text { Established market economies } \\
\text { (minus the United States) }\end{array}$ & 1.0 & 0.1 & 0.0 & 0.0 \\
Formerly socialist economies & 7.5 & 0.8 & 9.8 & 0.8 \\
India & 7.2 & 0.6 & 0.3 & $<0.05$ \\
China & 4.5 & 0.6 & 0.0 & $<0.05$ \\
Other Asia and islands & 7.5 & 0.9 & 2.0 & 0.3 \\
Sub-Saharan Africa & 44.8 & 2.5 & 52.9 & 3.3 \\
Latin America and Caribbean & 22.4 & 3.4 & 3.6 & 0.6 \\
Middle Eastern crescent & 7.7 & 0.9 & 33.2 & 3.7 \\
United States & 10.0 & 1.2 & 0.0 & 0.0 \\
World & 10.5 & 1.1 & 9.3 & 1.0 \\
\hline
\end{tabular}

SOURCE: Adapted from Reza, Mercy, and Krug (2001).

NOTE: Nations contained within each category (e.g., established market economies, formerly socialist economies) are provided in Reza, Mercy, and Krug (2001). Although rates of homicide are usually relatively stable, it is important to note here that these data do not reveal the tremendous increase in rates in the former Soviet Union in the early 1990s. Even after relative stabilization in the mid- to late 1990s, the homicide rate in this area would place it well above the United States and similar to that of Latin America and the Caribbean.

Two examples. Two brief examples of the burden to specific populations of homicide are provided here. First, violence-related morbidity and mortality among African Americans in the United States began to receive widespread attention as a serious public health issue in the 1980s and 1990s (Alcohol, Drug Abuse \& Mental Health Administration, 1980; Centerwall, 1984, 1992; Cook \& Laub, 1998; Geronimous, Bound, Waidmann, Hillemeier, \& Burns, 1996). Blacks in the United States have exhibited for generations high levels of excess mortality due to homicide. It is only relatively recently, however, that this has been afforded widespread notice as a public health concern.

Although homicide mortality in the United States declined throughout much of the 1990s, it is still several times that in other established market economies. A large component of this overall high rate is due to homicide among Blacks. In 1998, the overall age-adjusted death rate due to homicide in the United States was 7.3 per 100,000 population (Murphy, 2000). The rate for Whites 
was 4.4 per 100,000 , whereas the corresponding rate for Blacks was 25.2. The Black male rate was 43 per 100,000, and the Black female rate of 8.6 was 34\% higher than White males. Although homicide was not among the top 15 causes of death among Whites, it was number six among Blacks, and it was the number one killer of Blacks age 15 years to 24 years, with an age-specific rate of about 55 per 100,000. In general, the overall homicide rate in the United States is clearly a cause for concern among public health officials, especially when compared to similarly developed nations. More specifically, the homicide mortality rate among Blacks is simply unacceptable and demands focused attention in terms of research and intervention activities.

A second specific example is transitional Russia, where valid mortality data have only recently become available. Examination of these newly available records makes two things immediately clear. First, homicide mortality in Russia was not as low as previously advertised by Soviet officials, and recent research (Pridemore, 2001) reveals that homicide mortality in Russia has been comparable to or greater than in the United States for at least the past 35 years, and likely longer.

Second, homicide has emerged as an even more serious health threat as part of the general mortality crisis facing transitional Russia (for discussions of the mortality crisis, see Bobadilla, Costello, \& Mitchell, 1997; DaVanzo, 1996). During the transition years, violent death became one of the main components of the sharp reductions in life expectancy among males in Russia (Shkolnikov, Meslé, \& Vallin, 1997) and in other former Soviet nations (Kingkade \& Arriaga, 1997). The Russian homicide mortality rate more than tripled between 1988 and 1994, an unprecedented increase for a population during a time of peace, with the rate peaking at nearly 35 per 100,000 in 1994. Even after decreasing and then stabilizing somewhat in the late 1990s, the Russian homicide rate is still among the highest in the world.

Homicide victimization rates in Russia also show a curious age pattern, with men and women in their 30s, 40s, and 50s more at risk of homicide victimization than their younger counterparts (Pridemore, 2003). Thus, as with other forms of mortality during the transition (see Shkolnikov \& Meslé, 1996), working-age men, especially those age 25 years to 55 years, have fared the worst in terms of homicide mortality. At the peak of the crisis, the 
homicide mortality rate for Russian men in this age group was more than 75 per 100,000 . Although homicide mortality rates in Russia were relatively high before the transition, this precipitous rise certainly qualifies as a serious health threat among Russian citizens, especially working-age men.

\section{INTEGRATING SOCIOLOGICAL AND PUBLIC HEALTH PERSPECTIVES}

The fields of sociology and public health often overlap in their examination of violence. However, each offers unique substantive and methodological contributions to our understanding of the causes of violence and potential interventions that may reduce its harm. Until recently, these approaches have been mostly separate, with each (especially sociologists and criminologists) rarely citing the other's literature. The arguments made here are meant to spur debate over the integration of these perspectives and to suggest a shift from a multi- to an interdisciplinary approach in the study of violence and its prevention.

\section{Sociological Criminology}

In its study of violence, the main goal of sociological criminology is to develop causal theories from past observations and empirically evaluate their validity. This incremental process creates a better understanding of the underlying causal structure of the variation of homicide rates over time, from place to place, and among population groups. Furthermore, although most sociologists are not trained in designing and implementing interventions, many are methodologically equipped to empirically evaluate the efficacy of public health interventions and other policy implementations. Thus, theory construction and testing, together with policy and intervention analysis, might be the main roles for sociologically oriented criminologists in an integrated approach toward the causes and prevention of violence.

For most sociologists and criminologists, homicide is and always has been understood first and foremost as a crime, not as a

health outcome. ${ }^{5}$ Early work by Durkheim $(1893 / 1933)$ suggested that social conditions and social change may create higher rates of 
crime. In the United States, the work of Shaw and McKay (1942) led some criminologists to focus on the variation of crime rates among different areas. This means scrutinizing the social structural characteristics of places instead of the individual characteristics of offenders. This group-level approach is not meant to replace the study of individuals but instead to complement it and increase our understanding of how social structure, setting, and context influence individual behavior.

Most criminologists and sociologists who study violence believe that examining group-level and community characteristics is vital to understanding the patterns and antecedents of homicide rates. The past 30 years of research on social structure and homicide make it clear that place matters. Aside from the distribution of people and resources, group-level dynamics are also important in the study of violent encounters. For example, contextual analysis reveals that factors such as collective efficacy among community members can serve to mediate homicide rates in otherwise seriously deprived neighborhoods (Sampson, Raudenbush, \& Earls, 1997). In addition, interpersonal interactions are often conditioned by the location and social setting in which they occur (see Kennedy \& Forde, 1999), and normative expectations and behavioral responses vary from place to place (Anderson, 1999). These social characteristics can easily make the difference (given similar initial actions and microconditions) between a violent and nonviolent resolution or between an assault and a homicide.

However, social features, such as "the proportion of the population living in poverty" or "social cohesion," have never committed a homicide. Individuals, not sociological concepts, commit and are victims of murder. So, long-term goals of sociologists who study homicide not only include understanding how structural factors operate to cause higher homicide rates in certain areas but also how these group-level effects translate into risk and protective factors for potential homicide victims and offenders.

Much of the substantive knowledge about homicide developed by criminologists and sociologists mirrors that developed by public health researchers and epidemiologists about diseases. For example, both are beginning to more fully recognize multiple levels of causation (see Diez-Roux, 1998), and both often look to the same structural covariates of health outcomes, such as 
deprivation and social capital (Kawachi et al., 1999), whether those outcomes are diseases or violent victimizations. Moreover, where epidemiologists recognize that exposure early in life may lead to higher risks of developing a disease later on, the life course approach of some criminologists and sociologists stresses that what happens earlier in one's life might increase the risk of offending or victimization later in life (see Sampson \& Laub, 1993; Widom, 1989).

A final example includes complex interaction effects. From medical research, we know that in some cases all those infected with a disease-causing agent are not at equal risk of developing the condition. Genetic or other factors may act as a protective mechanism. Likewise, although the relationship between aggregate levels of poverty and homicide rates is probably the most consistent finding in the literature on social structure and homicide (Sampson \& Lauritsen, 1994), all individuals or families or communities with similar levels of poverty (e.g., equal household income) do not face the same risk of homicide mortality. Research in the United States suggests that despite their own poverty, those living in lower middle-class or middle-class areas have a much lower risk of offending or victimization than those living in areas of concentrated poverty (Fingerhut, Ingram, \& Feldman, 1992; Rose \& McClain, 1990). In the United States, the former is usually a White family and the latter a Black family (Peterson \& Krivo, 1999). Overall, where one lives, and thus his or her risk of violent injury or death, is often socially determined to a large degree (Peterson \& Krivo, 2000; Shihadeh \& Steffensmeier, 1994), and this is a clear example of how place and social structure matter.

For sociological criminologists, heeding the literature of other disciplines (and complementing it with our own), should increase our own repertoire of knowledge, encourage more theoretical creativity and innovation, and allow our research findings to produce tangible beneficial results.

\section{Public Health}

Although discussions of violence have appeared in the public health literature for decades, it has been a peripheral topic in the discipline until recently. This is largely the result of our traditional view of violence and homicide only as a crime, and thus as a 
social, rather than a public health, concern. However, although external in nature, violence-related morbidity and mortality are no less a threat to physical and mental health, and the sources of many other illnesses and deaths studied by epidemiologists are also external and created by humans. The public health perspective's focus on violence and homicide as types of morbidity or mortality (not simply as a crime) has lent a new and rejuvenating approach, especially because a main public health goal is harm reduction, not just scientific knowledge.

Public health has a tradition of focusing on individual risk and protective factors. This is important, because sociologists often have difficulty making the leap from aggregate population features to individual action or victimization. As mentioned earlier, however, the distribution of the lifestyle and risk factors of individuals are largely socially patterned (see Bobak \& Marmot, 1996). Thus, there has been a shift in public health toward realizing the role of the social environment in the incidence and prevalence of morbidity and mortality, including violence (Diez-Roux, 1998). It is obvious that "places in which people live are important for their health" (Siegrist, 2000, p. 1283) and that there are sizeable differences in health outcomes between and within populations (see Catalano \& Pickett, 2000; MacIntyre, MacIver, \& Sooman, 1993).

Specifically, Mercy and Hammond (1998) list the following as the main contributions of public health to the study of violence:

1. An emphasis on and commitment to violence prevention.

2. Prevention strategies that are based on sound scientific evidence.

3. Acting in an interdisciplinary manner to integrate information from several fields and use it to create efficient, cost-effective, and complementary responses.

4. Providing effective health services that mitigate the physical and psychological injuries of victims of violence.

5. A commitment to recognizing the important role of communities in responding to violence.

From this, we see that the public health perspective is action oriented, and its main goal is analysis of scientific evidence to improve injury prevention and violence reduction. This goal may be more immediately achievable through the use of traditional pub- 
lic health tools, even when the exact nature of the causal mechanisms is not completely understood. This perspective is generally outlined in Figure 1. To carry out the contributions outlined earlier, the first major task of public health and epidemiology is to define the problem and create a surveillance system for its accurate measurement. These data are then used to track patterns and discover risk and protective factors for a particular health outcome. This step may not always clearly display underlying causes, but it will likely identify those groups most at risk, as well as proximate risk factors. Given these results, intervention strategies can be designed to reduce and prevent harm. These interventions are evaluated for their effectiveness in meeting their goals of harm reduction and are subjected to cost-benefit analysis, with successful and cost-effective strategies promulgated.

For example, homicide rates rose considerably in the United States in the mid-1980s to early 1990s. By disaggregating the overall victimization rates into gender- and age-specific categories, researchers discovered that homicides among young Black men were responsible for nearly the entire increase. Furthermore, death records revealed that guns were the weapon of choice in more than three fourths of the homicides among this group. Community and governmental strategies aimed at reducing gang involvement, the crack trade, and gun availability became common in urban areas throughout the country. ${ }^{6}$ Those interventions deemed successful were often copied in other communities. Although the efficacy of many of these programs is debatable, and although rates of homicide mortality among Blacks are still unacceptably high, homicide rates have fallen substantially among this group in the past 10 years.

Criminological research makes it clear that the causes and effects of violence occur at several levels, and thus any intervention strategy must be as clear as possible in defining its target. Based on this, Mercy and Hammond (1998) extended the work of Tolan and Guerra (as cited in Mercy \& Hammond, 1998), who created a classification of violence prevention programs for adolescents based on various risk factors of violence at different levels. These levels include the personal (e.g., individual factors), the parochial (e.g., interpersonal relationships and proximate social settings), and the public (e.g., social structure and institutions, or macrosystems). Mercy and Hammond also borrow from the work 


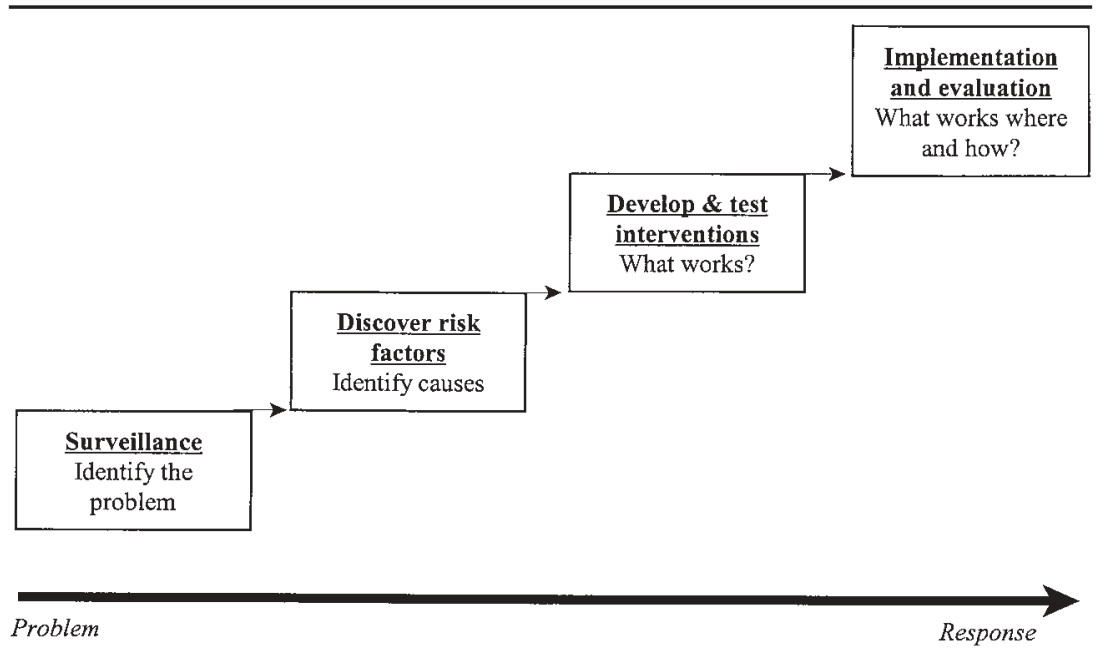

FIGURE 1. The public health approach to violence and injury prevention SOURCE: Adapted from World Health Organization (2001b).

of Gorden (1983) for their typology of preventive measures, which are based on the groups at which the interventions are aimed: universal (i.e., measures such as laws or campaigns directed at everyone in a population), selective (i.e., measures aimed at those with above-average risk), and indicated (i.e., measures for those at especially high risk or who are already violent offenders or victims). Mercy and Hammond thus created a matrix with suspected causal influences placed vertically and types of preventive measures placed horizontally, with the respective cells containing specific intervention strategies that are relevant to each influencing agent (see Table 19.3 in Mercy \& Hammond, 1998).

From this matrix, interventions can target individuals, families, schools, communities, and even nations. At the individual level, Thompson, Simon, Saltzman, and Mercy (1999) found that women employing self-protective behaviors were at less risk of violent injury than those who did not use such measures or who did so only after experiencing such an injury. At the family level, Ellis and DeKeseredy (1997) argued that although interventions with male sociopathic batterers will prove problematic, strategies that increase the social and legal costs to chronic/sporadic batterers are more likely to result in their entrance into intervention programs and thus reduce the risk of homicide to their female 
partners. Wilson's (2000) meta-analysis reveals that school violence prevention and treatment programs that focus on self-control/anger management and on classroom management are able to substantially reduce aggressive and disruptive behavior.

At the community level, research by O'Donnell et al. (1999) reveals that school-based interventions that also incorporated community service (in this case, service in health care programs) were more successful than school-based programs alone in reducing the risk of violent behavior among at-risk adolescents. On an even broader scale, preliminary research suggests that the nationwide antialcohol campaign in Russia during the mid- to late 1980s was associated with a sharp reduction of homicide rates in the country (Nemtsov, 1998; Pridemore, 2003). Other policy-based successes include the reduction of gang violence via aggressive enforcement of curfew and truancy ordinances (Fritsch, Caeti, \& Taylor, 1999), and the $25 \%$ reduction in homicides committed with a firearm as a result of restrictive handgun licensing in Washington, D.C. (Loftin, McDowall, Wiersema, \& Cottey, 1991).

These are just a few examples of the different types of intervention programs that can be successful at differing levels in reducing violence-related morbidity and mortality. As the public health approach to injury prevention and violence reduction continues, and as the sociological/criminological and public health perspectives work together to identify the causes of violence and the most effective interventions, we are likely to see more successes.

\section{SUMMARY AND CONCLUSIONS}

As an example of the increasing attention paid to violence by the public health community, the World Health Organization (2002) has recently released its World Health Report on Violence and Health and has undertaken a global campaign on violence prevention. Calls for an integrated approach to this problem are coming from other directions as well. For example, in a note outlining the foci and activities of the new Committee on Emerging Health Threats of the International Union for the Scientific Study of Population, Shkolnikov (a demographer) (2001) stated that a primary aim of the committee is to promote extensive scientific exchange in understanding the causal relationships that drive existing and 
emerging health threats. This includes a special focus on socioeconomic inequalities in mortality and health and on the global burden of injuries and violence. He went on to state that such sweeping goals demand collaboration between scientists from many disciplines. Similarly, the authors (public health researchers) of the lead paper on that panel stated that new public health demands "will require new ways of working, drawing on diverse methods and the skills of many different disciplines" (McKee \& Nolte, 2001, p. 6).

This conceptual article suggests that violence is a serious health threat in many populations and that it has extensive negative physical, emotional, social, and economic consequences. In many nations of sub-Saharan Africa, Latin America, and the former Soviet Union, homicide is among the leading causes of death, especially for certain demographic groups. The health burden of homicide in the United States is several times that in other developed market economies, and the risk of homicide for Blacks in the country is unacceptable in such a nation. Among some populations, such as African Americans in the United States, violence has posed a major public health threat for decades, although we are only now recognizing it as such. Among others, such as workingage men in transitional Russia (Pridemore, 2003), homicide and other violence has recently emerged as a heightened health threat. Sociological criminology and public health must work together to respond to both types of situations.

Human beings do not behave like atoms (i.e., always acting in the same manner given a seemingly similar set of initial conditions), thus making it difficult to predict homicide at the individual level. Furthermore, human interaction inevitably leads to violent encounters, and thus a baseline homicide rate is to be expected. However, homicide is an external cause of death that exhibits consistent demographic, temporal, and spatial patterns. In other words, homicide is not necessarily a random event but instead is a patterned cause of death with antecedents that can be empirically determined. It is thus a preventable form of mortality, and the burden of violence can therefore be minimized via public health interventions, especially among those populations with high levels of excess mortality resulting from it. It is true that sociologists are theory oriented and that they deal with social characteristics that many believe are not easily amenable to change. 
Public health, however, has a history of successfully applying scientific knowledge to implement efficacious intervention strategies that involve changing institutional (e.g., food and water safety, product warning labels) and individual behaviors (e.g., seat-belt usage, smoking) that are difficult to influence.

Sociological criminologists can reveal patterns of homicide and discover how they covary with group-level processes and social structural conditions, thereby better understanding its causal structure. In addition, the traditionally interdisciplinary approach of public health provides the tools to discover both individual and social risk and protective factors and develop effective intervention strategies that can reduce the public health burden of violence. As scientists, sociologists, and criminologists should be conservative in their claims about the underlying causal mechanisms of higher homicide rates. However, much like the original battles against certain diseases (e.g., tuberculosis and AIDS), public health officials do not need to wait for decades to understand exactly the causal mechanism of the threat but can observe the most proximate risk factors and respond to them appropriately to diminish the consequences, while at the same time providing clues to causes. This enables us to reduce the risk of lethal violence in the short term while attempting to understand the underlying causal mechanisms more fully in the long term. In sum, despite difficulties in doing so, an integration of the sociological/criminological and public health perspectives should be synergistic, allowing us to improve our understanding of and response to the heavy burden of homicide and other types of violence.

\section{NOTES}

1. Although this discussion is itself discipline centered, because it focuses on sociologically oriented criminology, similar arguments can be made about other fields that study crime and victimization. Public health, on the other hand, has a tradition of cooperating with other disciplines to carry out its goal of harm reduction. Increasingly, public health is directing attention to violence, and discussions such as this are becoming more common between public health and various disciplines that engage in research on violence.

2. According to estimates from the Global Burden of Disease Project (Murray \& Lopez, 1996), there were 500,000 war-related deaths worldwide in 1990, representing a mortality rate of about 9 per 100,000 population. Although these deaths play a major role in excess mortality due to violence, we do not normally think of them as interpersonal in nature, and thus the topic receives little attention from criminologists. As such, this issue is not discussed here. However, although the overarching causes of war are rarely responsive to 
public health interventions, public health officials and researchers are keenly interested in war-related health issues. Among the many war-related topics examined by public health researchers, for example, is the harm inflicted on the health of civilians, with decreased access to the essentials of life- such as food, water, and shelter-and the disruption of (often already tenuous) health care systems that might otherwise protect them from general health problems (see Carballo, Simic, \& Zeric, 1996; Garfield, Frieden, \& Vermund, 1987; Levy \& Sidel, 1997). Furthermore, because they can cause injuries and deaths for years after conflict has ceased, land mines are another result of war that have recently received attention in this literature (see Kakar, Bassani, Romer, \& Gunn, 1996; Levy \& Sidel, 1997).

3. A quick review of public health, epidemiological, and medical journals during the past 10 years reveals a growing number of articles focusing on violence, with risk and protective factors and the efficacy of interventions being the most popular. Although this is promising, many obstacles remain. The most serious is the dearth of relevant and / or valid data on violence and populations. Unfortunately, this is usually most apparent where rates of mortality due to violence are the highest, often in developing nations (Mercy \& Hammond, 1998). Reliable information on mortality by cause is vital for effective public health planning, yet these data are limited or of questionable value in too many nations. Thus, before we can begin to examine causal structures and intervention strategies, an immediate goal must be the construction of fundamental information infrastructures. This begins with injury surveillance systems that effectively measure the incidence and prevalence of violent events and their health outcomes (although even with the creation of such networks, effective responses are often slow in following due to a number of reasons, including resources and politics). Similar systems have been developed under difficult circumstances for other serious health threats, and they must be created for injuries and violence, as well.

4. A dictionary of epidemiology (Last, 1995) defines a dose-response relationship as "a relationship in which change in amount, intensity, or duration of exposure is associated with a change- - either an increase or a decrease-in risk of a specified outcome" (p. 49).

5. A recent exception to this is Zimring and Hawkins (1997), who argued that lethal violence is unique and that we should distinguish between violence and other types of crime when trying to understand elevated rates of homicide, especially in the United States.

6. Ready access to firearms may create a serious public health issue in certain areas and an increased risk of lethal violence in some social settings (Kellerman et al., 1993; Sorenson \& Berk, 1999). Although the presence of a firearm is rarely the cause of violent acts, the availability of such a lethal force may escalate the event and turn an assault into a homicide (see Cook, 1991). Villaveces et al. (2000) and the National Center for Injury Prevention and Control (2001) show that gun homicides represent about $70 \%$ to $80 \%$ of homicides in the United States, whereas an earlier study of African Americans in one U.S. state revealed that more than $70 \%$ of years of the potential life lost among Blacks attributable to homicide was due to firearms (Centers for Disease Control, 1989).

\section{REFERENCES}

Adams, R. E., \& Serpe, R. T. (2000). Social integration, fear of crime, and life satisfaction. Sociological Perspectives, 43, 605-629.

Alcohol, Drug Abuse \& Mental Health Administration. (1980). Homicide among Black males: Highlights of the symposium sponsored by the Alcohol, Drug Abuse and Mental Health Administration. Public Health Reports, 95, 549-561. 
Anderson, E. (1999). Code of the street: Decency, violence, and the moral life of the inner city. New York: Norton.

Berkman, L. F., \& Kawachi, I. (Eds.). (2000). Social epidemiology. New York: Oxford University Press.

Bobadilla, J. L., Costello, C. A., \& Mitchell, F. (1997). Premature death in the New Independent States. Washington, DC: National Academy Press.

Bobak, M., \& Marmot, M. (1996). East-West mortality divide and its potential explanations: Proposed research agenda. British Medical Journal, 312, 421-425.

Carballo, M., Simic, S., \& Zeric, D. (1996). Health in countries torn by conflict: Lessons from Sarajevo. Lancet, 348, 872-874.

Catalano, R., \& Pickett, K. E. (2000). A taxonomy of research concerned with place and health. In G. L. Albrecht, R. Fitzpatrick, \& S. C. Scrimshaw (Eds.), The handbook of social studies in health and medicine (pp. 60-82). London: Sage.

Centers for Disease Control. (1989). Topics in minority health: Impact of homicide on years of potential life lost in Michigan's Black population. Morbidity and Mortality Weekly, 38(1), 4-6, 11.

Centerwall, B.S. (1984). Race, socioeconomic status, and domestic homicide, Atlanta, 197172. American Journal of Public Health, 74, 813-815.

Centerwall, B. S. (1992). Race, socioeconomic status, and domestic homicide. Journal of the American Medical Association, 273, 1755-1758.

Cherpitel, C. J. (1993). Alcohol and violence-related injuries: An emergency room study. Addiction, 88, 79-88.

Cook, P. J. (1991). The technology of personal violence. In M. Tonry (Ed.), Crime and justice: A review of research (Vol. 14, pp. 1-72). Chicago: University of Chicago Press.

Cook, P. J., \& Laub, J. H. (1998). The unprecedented epidemic in youth violence. Crime and Justice, 24, 27-64.

Cook, P. J., \& Ludwig, J. (2000). Gun violence: The real costs. New York: Oxford University Press.

DaVanzo, J. (1996). Russia's demographic “crisis." Santa Monica, CA: RAND.

Diez-Roux, A. V. (1998). Bringing context back into epidemiology: Variables and fallacies in multi-level analysis. American Journal of Public Health, 88, 216-222.

Durkheim, E. (1933). The division of labor in society (G. Simpson, Trans.). New York: Free Press. (Original work published 1893)

Ellis, D., \& DeKeseredy, W.S. (1997). Rethinking estrangement, interventions, and intimate femicide. Violence Against Women, 3, 590-609.

Felitti, V. J. et al. (1998). Relationship of childhood abuse and household dysfunction to many of the leading causes of death in adults: The Adverse Childhood Experiences (ACE) study. American Journal of Preventive Medicine, 14, 245-258.

Fingerhut, L. A., Ingram, D. D., \& Feldman, J. J. (1992). Firearm and nonfirearm homicide among persons 15 through 19 years of age: Differences by level of urbanization, United States, 1979 through 1989. Journal of the American Medical Association, 267, 3048-3053.

Fritsch, E. J., Caeti, T. J., \& Taylor, R. W. (1999). Gang suppression through saturation patrol, aggressive curfew, and truancy enforcement: A quasi-experimental test of the Dallas anti-gang initiative. Crime $\mathcal{E}$ Delinquency, 45, 122-139.

Garfield, R. M., Frieden, T., \& Vermund, S. H. (1987). Health-related outcomes of war in Nicaragua. American Journal of Public Health, 77, 615-618.

Geronimous, A. T., Bound, J., Waidmann, T. A., Hillemeier, M. M., \& Burns, P. B. (1996). Excess mortality among Blacks and Whites in the United States. New England Journal of Medicine, 335, 1552-1558.

Gorden, R. (1983). An operational classification of disease prevention. Public Health Reports, 98, 107-109. 
Hawkins, J. D., Catalano, R. F., \& Miller, J. Y. (1992). Risk and protective factors for alcohol and other drug problems in adolescence and early adulthood: Implications for substance abuse prevention. Psychological Bulletin, 112, 64-105.

Horwitz, A. V., Widom, C. S., McLaughlin, J., \& White, H. R. (2001). The impact of childhood abuse and neglect on adult mental health: A prospective study. Journal of Health and Social Behavior, 42, 184-201.

Johnson, K. (1996). The politics of the revival of infant abandonment in China, with special reference to Hunan. Population and Development Review, 22, 77-99.

Jones, M. B., \& Jones, D. R. (2000). The contagious nature of antisocial behavior. Criminology, 38, 25-46.

Kakar, F., Bassani, F., Romer, C. J., \& Gunn, S. W. (1996). The consequences of land mines on public health. Prehospital and Disaster Medicine, 11, 41-45.

Kaufman, J. G., \& Widom, C. S. (1999). Childhood victimization, running away, and delinquency. Journal of Research in Crime and Delinquency, 36, 347-370.

Kawachi, I., Kennedy, B. P., \& Wilkinson, R. G. (1999). Crime: Social disorganization and relative deprivation. Social Science and Medicine, 48, 719-731.

Kellerman, A. L. et al. (1993). Gun ownership as a risk factor for homicide in the home. New England Journal of Medicine, 329, 1084-1091.

Kennedy, L. W., \& Forde, D. R. (1999). When push comes to shove: A routine conflict approach to violence. Albany: State University of New York Press.

Kingkade, W. W., \& Arriaga, E. E. (1997). Mortality in the New Independent States: Patterns and impacts. In J. L. Bobadilla, C. A. Costello, \& F. Mitchell (Eds.), Premature death in the New Independent States (pp. 156-183). Washington, DC: National Academy Press.

Krug, E. (1999). Injury: A leading cause of the global burden of disease. Geneva, Switzerland: World Health Organization.

Last, J. M. (1995). Adictionary of epidemiology (3rd ed.). New York: Oxford University Press.

Levy, B. S., \&Sidel, V. W. (1997). War and public health. New York: Oxford University Press.

Loftin, C. (1986). Assaultive violence as a contagious social process. Bulletin of the New York Academy of Medicine, 62, 550-555.

Loftin, C., McDowall, D., Wiersema, B., \& Cottey, T. J. (1991). Effects of restrictive licensing of handguns on homicide and suicide in the District of Columbia. New England Journal of Medicine, 325, 1615-1620.

MacDonald, S., Wells, S., Geisbrecht, N., \& Cherpitel, C. J. (1999). Demographic and substance use factors related to violent and accidental injuries: Results from an emergency room study. Drug and Alcohol Dependence, 55, 53-61.

MacIntyre, S., MacIver, S., \& Sooman, A. (1993). Area, classes and health: Should we be focusing on places or people? Journal of Social Policy, 22, 213-234.

McKee, M., \& Nolte, E. (2001, August). Emerging diseases-The need for a new research framework. Paper presented at the International Union for the Scientific Study of the Population, Salvador de Bahia, Brazil. Retrieved from http://iussp.org/Brazil2001/s10/ S18_02_McKee.pdf

Mercy, J. A., \& Hammond, W. R. (1998). Combining action and analysis to prevent homicide: A public health perspective. In M. D. Smith \& M. A. Zahn (Eds.), Homicide: A sourcebook of social research (pp. 297-310). Thousand Oaks, CA: Sage.

Messner, S. F., Anselin, L., Baller, R. D., Hawkins, D. F., Deane, G., \& Tolnay, S. E. (1999). The spatial patterning of county homicide rates: An application of exploratory spatial data analysis. Journal of Quantitative Criminology, 15, 423-450.

Messner, S. F., \& Rosenfeld, R. (1999). Social structure and homicide: Theory and research. In M. D. Smith \& M. A. Zahn (Eds.), Homicide: A sourcebook of social research (pp. 27-41). Thousand Oaks, CA: Sage.

Murphy, S. L. (2000). Deaths: Final data for 1998. In National Vital Statistics Reports, 48(11). Hyattsville, MD: National Center for Health Statistics. 
Murray, C. J. L., \& Lopez, A. D. (Eds.). (1996). The global burden of disease: A comprehensive assessment of mortality and disability from diseases, injuries, and risk factors in 1990 and projected. Boston: Harvard School of Public Health.

National Center for Injury Prevention and Control. (2001). Leading causes of death reports. Retrieved from http://webapp.cdc.gov/sasweb/ncipc/leadcaus.html

Neapolitan, J. L. (1998). Cross-national variation in homicides: Is race a factor? Criminology, $36,139-156$.

Nemtsov, A. V. (1998). Alcohol-related harm and alcohol consumption in Moscow before, during, and after a major alcohol campaign. Addiction, 93, 1501-1510.

O'Donnell, L. et al. (1999). Violence prevention and young adolescents' participation in community youth service. Journal of Adolescent Health, 24, 28-37.

Peterson, R. D., \& Krivo, L. J. (1999). Racial segregation, the concentration of disadvantage, and Black and White homicide victimization. Sociological Forum, 14, 465-493.

Peterson, R. D., \& Krivo, L. J. (2000). The structural context of homicide: Accounting for racial differences in process. American Sociological Review, 65, 547-559.

Pridemore, W. A. (2001). Using newly available homicide data to debunk two myths about violence in an international context: A research note. Homicide Studies, 5, 267-275.

Pridemore, W. A. (2002). What we know about social structure and homicide: A review of the theoretical and empirical literature. Violence and Victims, 17, 127-156.

Pridemore, W. A. (2003). Demographic, temporal, and spatial patterns of homicide rates in Russia. European Sociological Review, 19, 41-59.

Reza, A., Mercy, J. A., \& Krug, E. (2001). Epidemiology of violent deaths in the world. Injury Prevention, 7, 104-111.

Rivara, F. P., Mueller, B. A., Somes, G., Mendoza, C. T., Rushforth, N. B., \& Kellerman, A. L. (1997). Alcohol and illicit drug abuse and the risk of violent death in the home. Journal of the American Medical Association, 278, 569-575.

Rose, H. M., \& McClain, P. D. (1990). Race, place, and risk: Black homicide in urban America. Albany: State University of New York Press.

Ross, C. E. (1993). Fear of crime and health. Journal of Quantitative Criminology, 9, 159-175.

Sampson, R. J., \& Laub, J. H. (1993). Crime in the making: Pathways and turning points through life. Cambridge, MA: Harvard University Press.

Sampson, R. J., \& Lauritsen, J. L. (1994). Violence, victimization, and offending. In A. J. Reiss \& J. J. Roth (Eds.), Understanding and preventing violence: Social influences (pp. 1-114). Washington, DC: National Academy Press.

Sampson, R. J., Raudenbush, S. W., \& Earls, F. (1997). Neighborhoods and violent crime: A multilevel study of collective efficacy. Science, 277, 918-924.

Schneiderman, N., Speers, M. A., Silva, J. M., Tomes, H., \& Gentry, J. H. (2001). Integrating behavioral and social sciences with public health. Washington, DC: American Psychological Association.

Shaw, C. R., \& McKay, H. D. (1942). Juvenile delinquency in urban areas. Chicago: University of Chicago Press.

Shihadeh, E. S., \& Steffensmeier, D. J. (1994). Economic inequality, family disruption, and urban Black violence: Cities as units of stratification and social control. Social Forces, 73 , 729-751.

Shkolnikov, V. (2001). The idea, aims and areas of activity of the IUSSP Committee on Emerging Health Threats. Retrieved from http://www.demogr.mpg.de/Events/workshops/ 001110_IUSSP.htm

Shkolnikov, V., \& Meslé, F. (1996). The Russian epidemiological crisis as mirrored by mortality trends. In J. DaVanzo (Ed.), Russia's demographic crisis (pp. 113-162). Santa Monica, CA: RAND.

Shkolnikov, V., Meslé, F., \& Vallin, J. (1997). Recent trends in life expectancy and causes of death in Russia, 1970-1993. In J. L. Bobadilla, C. A. Costello, \& F. Mitchell (Eds.), Premature death in the New Independent States (pp. 34-65). Washington, DC: National Academy Press. 
Siegrist, J. (2000). Place, social exchange and health: Proposed sociological framework. Social Science and Medicine, 51, 1283-1293.

Skog, O. J. (1986). Trends in alcohol consumption and violent deaths. British Journal of Addiction, 91, 365-379.

Sorenson, S. B., \& Berk, R. A. (1999). Young guns: An empirical study of persons who use a firearm in a suicide or a homicide. Injury Prevention, 5, 280-283.

Thompson, M. P., Simon, T. R., Saltzman, L. E., \& Mercy, J. A. (1999). Epidemiology of injuries among women after physical assaults: The role of self-protective behaviors. American Journal of Epidemiology, 150, 235-244.

Thornberry, T. P., Huizinga, D., \& Loeber, R. (1995). The prevention of serious delinquency and violence: Implications from the program of research on the causes and correlates of delinquency. In J. C. Howell, B. Krisberg, J. D. Hawkins, \& J. J. Wilson (Eds.), Serious, violent, and chronic juvenile offenders: A sourcebook (pp. 213-237). Thousand Oaks, CA: Sage.

Toch, H. (1992). Mosaic of despair: Human breakdowns in prison. Washington, DC: American Psychological Association.

Toch, H., \& Adams, K. (1991). Coping: Maladaptation in prison. New Brunswick, NJ: Transaction Books.

United Nations Centre for Human Rights. (1996). Fact sheet No. 23: Harmful traditional practices affecting the health of women and children. Geneva, Switzerland: United Nations High Commission for Human Rights.

United Nations Development Programme. (2001). Human development report: Making new technologies work for human development. New York: Oxford University Press.

Villaveces, A., Cummings, P., Espitia, V. E., Koepsell, T. D., McKnight, B., \& Kellerman, A. L. (2000). Effect of a ban on carrying firearms on homicide rates in 2 Colombian cities. Journal of the American Medical Association, 283, 1205-1209.

Widom, C. S. (1989). The cycle of violence. Science, 244, 160-166.

Wilson, S. J. (2000). Effectiveness of school violence intervention programs: Application of a mean change approach to meta-analysis. Unpublished doctoral dissertation, Department of Sociology, Vanderbilt University, Nashville, Tennessee.

World Bank. (2002). Country classification. Retrieved from http://www.worldbank.org/ data/countryclass/countryclass.html

World Health Organization. (2001a). 1997-1999 world health statistics annual. Retrieved from http://www-nt.who.int/whosis/statistics/menu.cfm?path=statistics,whsa\& language $=$ english

World Health Organization. (2001b). Violence and injury prevention. Retrieved from http:// www.who.int/violence_injury_prevention

World Health Organization. (2002). World health report on violence and health. Geneva, Switzerland: Author.

Zimring, F. E., \& Hawkins, G. (1997). Crime is not the problem: Lethal violence in America. New York: Oxford University Press.

William Alex Pridemore is an assistant professor of sociology at the University of Oklahoma, where he is also an affiliate faculty member of the School of International and Area Studies and a research associate with the Center for Crime and Justice Studies. His current research examines the effect of social structure, economic transition, and alcohol consumption on the cross-sectional and temporal variation of homicide and suicide rates in Russia. His recent publications have appeared in American Journal of Public Health, Journal of Research in Crime and Delinquency, and Social Science and Medicine. 